7-1-2011

\title{
A Silicon Nanoparticle-based Polymeric Nano-composite Material for Glucose Sensing
}

Qiang Liu

Cleveland State University

Munir H. Nayfeh

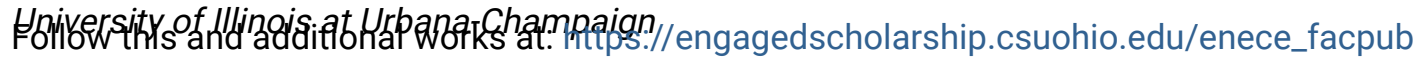

IFAritigfytau Biomedical Devices and Instrumentation Commons, and the Electrical and Computer Eleveland State University, s.yau@csuohio.edu

How does access to this work benefit you? Let us know!

\section{Publisher's Statement}

NOTICE: this is the author's version of a work that was accepted for publication in Journal of Electroanalytical Chemistry. Changes resulting from the publishing process, such as peer review, editing, corrections, structural formatting, and other quality control mechanisms may not be reflected in this document. Changes may have been made to this work since it was submitted for publication. A definitive version was subsequently published in Journal of Electroanalytical Chemistry, 657, 1-2, (07-01-2011); 10.1016/j.jelechem.2011.03.022

\section{Original Citation}

Q. Liu, M. H. Nayfeh and S. Yau, "A silicon nanoparticle-based polymeric nano-composite material for glucose sensing," J Electroanal Chem, vol. 657, pp. 172-175, 7/1, 2011.

\section{Repository Citation}

Liu, Qiang; Nayfeh, Munir H.; and Yau, Siu-Tung, "A Silicon Nanoparticle-based Polymeric Nano-composite Material for Glucose Sensing" (2011). Electrical Engineering \& Computer Science Faculty Publications. 218.

https://engagedscholarship.csuohio.edu/enece_facpub/218

This Article is brought to you for free and open access by the Electrical Engineering \& Computer Science Department at EngagedScholarship@CSU. It has been accepted for inclusion in Electrical Engineering \& Computer Science Faculty Publications by an authorized administrator of EngagedScholarship@CSU. For more information, please contact library.es@csuohio.edu. 


\title{
A silicon nanoparticle-based polymeric nano-composite material for glucose sensing
}

\author{
Qiang Liu ${ }^{\mathrm{a}}$, Munir H. Nayfeh ${ }^{\mathrm{b}}$, Siu-Tung Yau ${ }^{\mathrm{a}, *}$ \\ a Department of Electrical and Computer Engineering, Cleveland State University, Cleveland, $\mathrm{OH} 44115$, USA \\ ${ }^{\mathrm{b}}$ Department of Physics, University of Illinois at Urbana-Champaign, Urbana, IL. 61801, USA
}

\section{Introduction}

Today's glucose biosensors use the enzyme, glucose oxidase (GOx), as sensing element [1]. The primary issue of using GOx as sensing element is the inherent instability of the enzyme, which makes the enzyme prone to thermal and chemical deformation/ denaturation during fabrication, storage or use [2]. The changed enzyme conformation will produce detrimental effects on the in vivo performance of glucose biosensors [3]. For home-blood glucose monitoring, blood sample size of $3 \mu \mathrm{l}[4]$ is required to meet the sensitivity requirement of enzyme-based biosensors. The large sample size collected by pricking fingertips causes discomfort for patients and results in a low compliance rate of using the sensors by patients who needs several tests daily [5]. To reduce the discomfort, blood samples could also be collected in less sensitive regions of the body such as the forearm. Since the density of capillary vessels in these regions is much less than in the fingertips, the sample volume collected by one pricking action is much smaller than $3 \mu \mathrm{l}$ [5]. Thus, one of the priority tasks in glucose-sensor research is to work with much smaller samples while satisfying the sensor's sensitivity requirement. It is believed that inorganic sensing materials can be used to replace enzyme in order to eliminate the issues mentioned.

Recently, we have shown that the ultrasmall silicon nanoparticles (USiN), when deposited on a bare electrode, show the essential characteristics of glucose sensing element $[6,7]$. The most noted

* Corresponding author. Tel.: +1 216875 9783; fax: +1 2166875405 .

E-mail address: s.yau@csuohio.edu (S.-T. Yau). characteristic observed was that the glucose response of USiN is significantly higher than that of the enzyme GOx. Furthermore, USiN shows selectivity for glucose against major interference agents, and the sensing electrode provides long-term stability. In this article, we describe the synthesis of a nano-composite material (NCM) by incorporating USiN in polyaniline (PANI), a conducting polymer, in order to develop USiN as a practical sensing material for glucose sensing. Conducting polymers such as PANI with its nanoporous structure has been used as supporting materials for the dispersion of metal catalyst nanoparticles in order to prepare high performance electrocatalytic materials [8]. Conducting polymers adhere firmly to electrodes and show stability under device operation [9]. In the present work, the NCM was developed to control and optimize the amount of USiN on the sensing electrode in order to control the sensing signal level. The incorporation of USiN in PANI resulted in a three-dimensional (3D) loading of the particle. Additionally, PANI offers an anchorage for USiN to be firmly attached to the electrode and PANI works as nanowires for transmitting electrons collected from glucose to the electrode. We show that electrodes coated with NCM possess three essential properties for glucose sensing: (1) significantly enhanced amperometric response to glucose, (2) a wide linear range of the amperometric response that covers both the hypo- and hyper-glycaemic glucose levels, and (3) glucose selectivity against major interference agents existing in the body fluid. As a demonstration of the potential applications of the composite material in glucose sensing, small-volume glucose samples were used to characterize the composite material's glucose amperometric response, which showed similar sensitivity as that obtained with large-volume samples. 
The NCM electrode's long-term in vitro glucose response appeared to be reasonably stable. Our results indicate that the composite material is a novel non-enzyme sensing material for glucose sensing applications.

\section{Materials and methods}

USiN were made by electrochemical etching of a $\left(\begin{array}{lll}1 & 0 & 0\end{array}\right)$-oriented p-type (1-10 $\Omega \mathrm{cm}$ ) silicon wafer in hydrofluoric acid and hydrogen peroxide followed by shaking off the particles from the etched wafer using ultrasound in water or organic solvents such as benzene, isopropyl alcohol and tetrahydrofuran (THF) [10]. This etching technique can be used to prepare 1 -nm particles (USiN1) and 2.8-nm particles (USiN2.8), depending on etching conditions. Under UV excitation, USiN1 generates blue spontaneous emission with a measured band-gap of $3.5 \mathrm{eV}$ and USiN2.8 generates red emission with a $2 \mathrm{eV}$ band-gap. Fig. 1a shows the spontaneous emissions of the two kinds of particle. Monte Carlo simulation of the USiN1 particle suggests a filled fullerene structure of $\mathrm{Si}_{29} \mathrm{H}_{24}$, in which a central core silicon atom and four other silicon atoms are arranged in a tetrahedral coordination and the 24 remaining silicon atoms undergo a $\mathrm{H}$-terminated bulk-like $(2 \times 1)$ reconstruction of dimer pairs on $\left(\begin{array}{lll}0 & 0 & 1\end{array}\right)$ facets (six reconstructed surface dimers) [11].

Polyaniline (PANI) was prepared by electrochemical polymerization of aniline monomers (Sigma Aldrich) [12] on heavily doped $(\rho<0.005 \Omega \mathrm{cm})$ n-type silicon wafers, which contained the native oxide. The wafers were first cleaned with ethanol, isopropanol and de-ionized water and then covered with a mask to achieve a working area of about $1 \mathrm{~mm} \times 1 \mathrm{~mm}$ for the polymerization process. The polymerization was carried out in an electrochemical cell with the silicon wafer as the working electrode. The deposition of PANI films was obtained by cycling the cell potential between 0 and $0.8 \mathrm{~V}$ at $50 \mathrm{mV} / \mathrm{s}$ for 1000 cycles in a solution that contained $0.1 \mathrm{M}$ aniline and $1 \mathrm{M} \mathrm{HCl}$. The nano-composite was prepared by first mixing a water-based USiN $(10 \mu \mathrm{M})$ with a solution, which contained $0.1 \mathrm{M}$ of aniline and $1 \mathrm{M} \mathrm{HCl}$ (with a volume ratio of $6: 4$ ), followed by performing the electrochemical polymerization described to co-deposit the composite material on silicon wafers.

The electrochemical cell was a conventional three-electrode cell, controlled by a potentiostat ( $\mathrm{CH}$ Instrument 660C). A commercial $\mathrm{Ag} / \mathrm{AgCl}(3 \mathrm{M} \mathrm{KCl}$ ) electrode was used as the reference electrode, and a platinum wire was used as the counter electrode. Cyclic voltammetry measurements were performed with the potential scanned at $50 \mathrm{mV} / \mathrm{s}$. Detection of glucose was performed with silicon wafers containing the nano-composite material as the working electrode. Glucose was dissolved in a phosphate buffer solution (PBS) and then introduced into the cell for measurements. De-ionized water ( $\rho=18.2 \mathrm{M} \Omega \mathrm{cm}$, Direct Q3, Millipore) was used to prepare $100 \mathrm{mM}$ PBS at $\mathrm{pH}$ 7. The 0.015 in-diameter $\mathrm{Ag} / \mathrm{AgCl}$ wire that was used as the reference electrode for the small-volume measurement was purchased from A-M Systems (Sequim, WA). A pipette (Eppendorf), which transfers $0.5-20 \mu$ sample, was used to collect the $1 \mu \mathrm{l}$ samples. Scanning electron microscopy (SEM) was performed using an Amray 1820 instrument. The voltammetric measurements presented here were made at room temperature under de-aerated condition.

\section{Results and discussion}

The morphologies of the electrochemically synthesized PANI and nano-composite material have been studied using SEM. Fig. 1b shows that the electrochemically synthesized PANI has a fibrillar morphology with a cross-sectional dimension of about $150 \mathrm{~nm}$ as previously noted [13]. As shown in Fig. 1c, the nano-
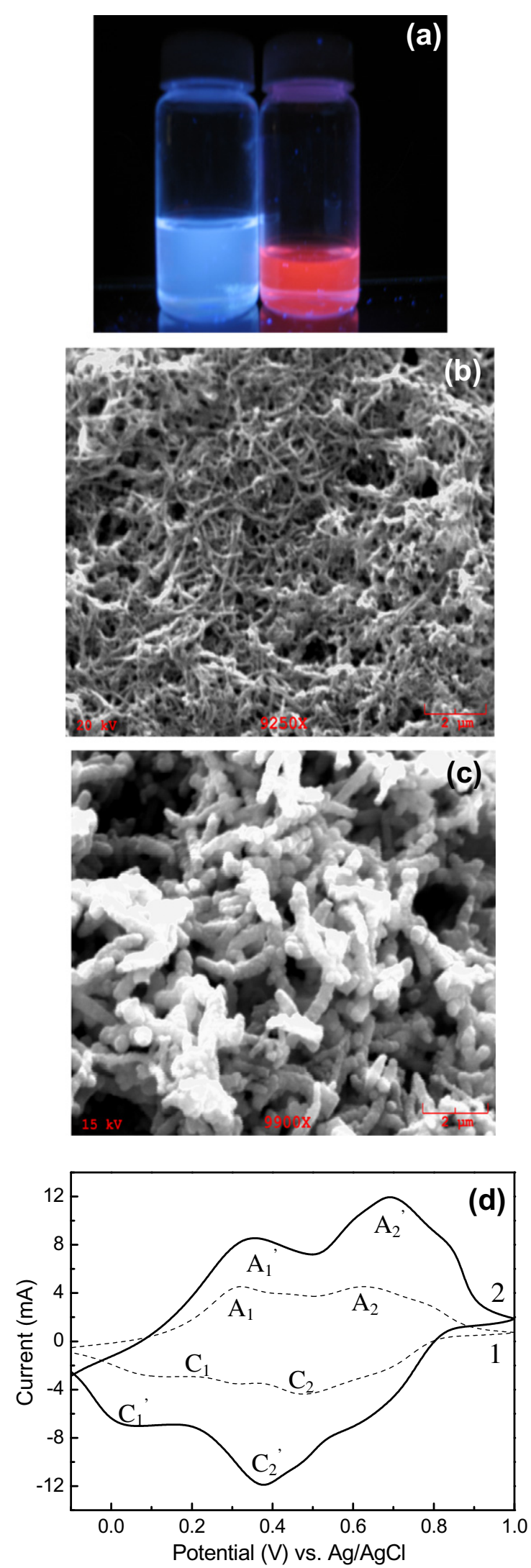

Fig. 1. (a) Spontaneous emission of USiN1 and USiN2.8 under UV excitation, (b) SEM image of the electropolymerized PANI, (c) SEM image of the nano-composite material, (d) Cyclic voltammograms of the electropolymerized PANI (CV1) and the nano-composite material (CV2) deposited on silicon wafers under acidic conditions $(1 \mathrm{M} \mathrm{HCl})$. The two pairs of redox peaks, which are characteristics of PANI, appear in both CVs. 
composite material also appears to have a fibrillar morphology. However, the fibers have a much larger cross-sectional dimension of about $600 \mathrm{~nm}$, which was the result of incorporating USiN2.8 in PANI during the electropolymerization process.

Control electrochemical experiments were performed with bare silicon wafers and PANI deposited on silicon electrodes, which showed no electrochemical response to glucose up to a potential as high as $1.6 \mathrm{~V}$. Cyclic voltammetry was performed with electrodes containing PANI and the nano-composite material in order to confirm the formation of the electrochemically synthesized PANI. Fig. 1d shows the cyclic voltammograms (CV) of the two types of electrodes obtained under acidic condition. CV1, obtained with a PANI electrode, shows two pairs of redox peaks, $A_{1} / C_{1}$ and $A_{2} / C_{2} . A_{1} / C_{1}$ indicates the transition between leucoemraldine and emeraldine salt and $A_{2} / C_{2}$ indicates the transition between emeraldine salt and pernigraniline [14]. The redox peaks are characteristics of PANI. CV2 was obtained with a USiN1-based NCM electrode. It appears that the two pairs of redox peaks are now superimposed on a plateau to become $\mathrm{A}_{1}^{\prime \leftarrow} / C_{1}^{\prime \leftarrow}$ and $\mathrm{A}_{2}^{\prime \leftarrow} / \mathrm{C}_{2}^{\prime \leftarrow}$. It is obvious that the current level of CV2 in the plateau region is much higher than that of CV1.

The response of the NCM electrode to glucose was studied using cyclic voltammetry at pH 7. Fig. 2a shows the CV (CV1) of a USiN1based NCM electrode in PBS only and that in $4 \mathrm{mM}$ glucose (CV2). CV2 shows a higher anodic current above CV1 beyond a threshold of $0.18 \mathrm{~V}$, indicating the catalytic ability of the electrode for glucose [6]. Note that pure PANI and bare silicon wafers showed no amperometric response to glucose in the potential range used here. In Fig. 2b, Curve 1 is the glucose calibration curve of the NCM electrode used in Fig. 2a while Curve 2 is that of an electrode immobilized with physically adsorbed USiN1 [6]. Curve 1 shows a current density level which is on the average six times higher than that of Curve 2. We attribute the significantly enhanced glucose response provided by the NCM electrode to the 3D loading of USiN1 in PANI. Curve 3 is the glucose calibration curve of an electrode immobilized with GOx [6]. It is obvious that Curve 1 shows a much larger glucose response compared to both Curve 2 and Curve 3. USiN2.8 produces similar response to glucose. Note that the absence of the saturation region in Curve 1 and Curve 2 shows the superior glucose oxidation capability of NCM as explained previously [6].

The augmented loading of USiN has resulted in a wide linear range in the calibration curve. Fig. $2 \mathrm{~b}$ shows that between $0.5 \mathrm{mM}$ and $50 \mathrm{mM}$ the current density shows a linear dependence on glucose concentration with a correlation coefficient $r=0.9886$. This range covers both the hypo- and hyper-glycaemic levels [15]. The detection limit was estimated to be $14 \mu \mathrm{M}$ according to a signal-to-noise ratio of 3 . The sensitivity of the electrode is $2.5 \mu \mathrm{Acm}^{-2} \mathrm{mM}^{-1}$, which is comparable to the sensitivity of enzyme-based glucose biosensors[16].

Previously, the selectivity for glucose against major interfering agents in body fluid such as ascorbic acid (AA), uric acid (UA) and 4-acetamidophenol (AP) at the physiological levels has been demonstrated as a sensing property of USiN [6]. In the present work, the nano-composite material showed glucose selectivity only against UA and AP. In this work, it was observed that PANI was able to oxidize AA as observed previously [17]. The total selectivity of the nano-composite material for glucose against the interfering agents can be provided, as previously shown, by either coating the sensing material with a thin layer of Nafion as an effective perm-selective membrane[18] or by dispersing Nafion solution in the sensing material [12]. In this work, the first approach was adopted. In Fig. 2c, CV1 was obtained in PBS with a USiN1based NCM electrode that was covered with a Nafion membrane. CV2 and CV3 were obtained using the same electrode under different conditions. CV2 was obtained in $4 \mathrm{mM}$ glucose while CV3 was obtained a solution that contained $4 \mathrm{mM}$ glucose and the physio-
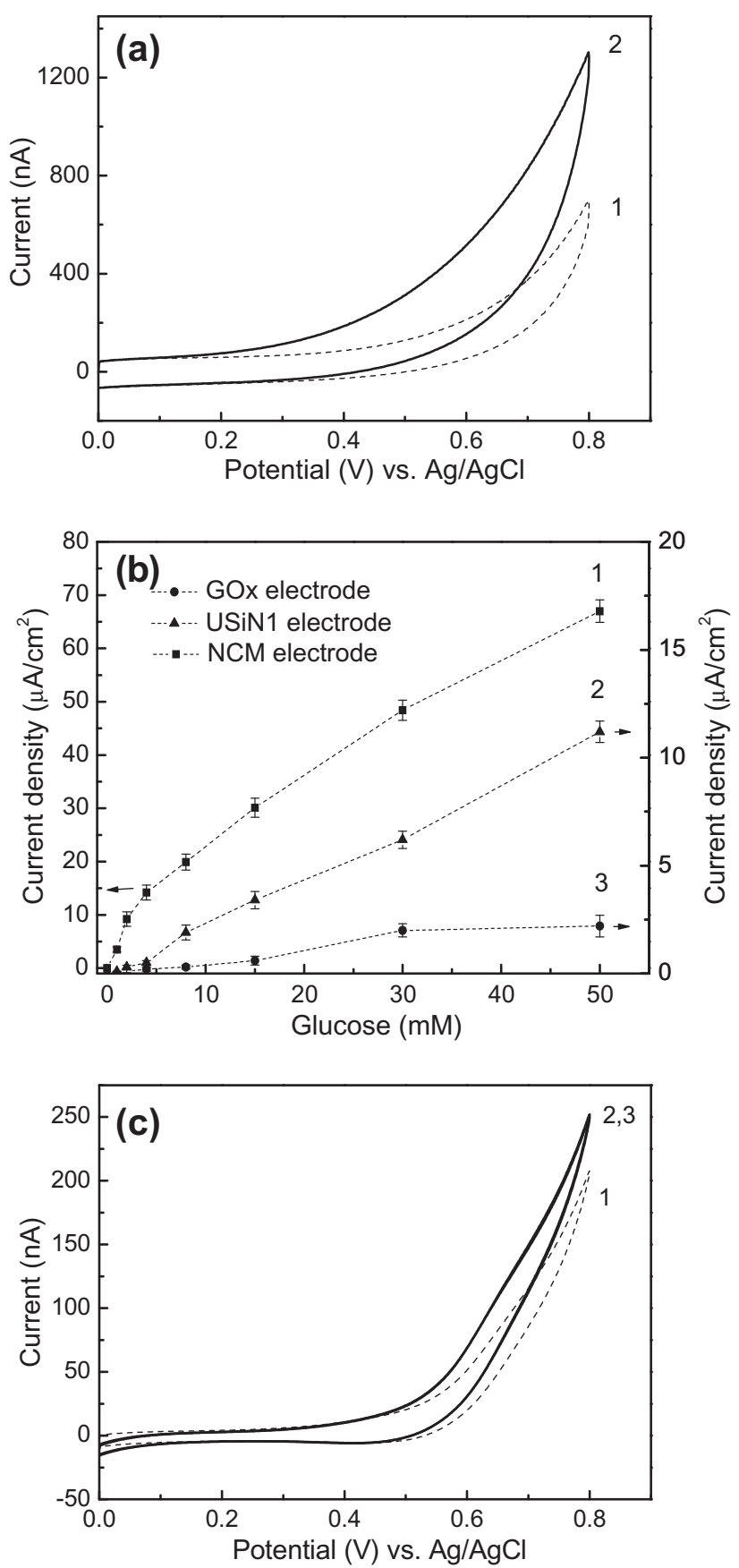

Fig. 2. (a) CV1 and CV2 were obtained with the NCM electrode. CV1 was obtained in PBS while CV2 in $4 \mathrm{mM}$ glucose. CV2 shows the electrode's response to glucose. (b) Curve 1 is the glucose calibration curve of the NCM electrode. Curve 2 and Curve 3 are the glucose calibration curves of a USiN1-immobilized silicon electrode and a GOx-immobilized silicon electrode, respectively. Curve 2 and Curve 3 are taken from Ref. [4] and used here for comparison purposes. The current values of the calibration curves were taken at a potential of $0.7 \mathrm{~V}$. The dashed lines are used as guides to the eye. (c) CV1 was obtained in PBS with a NCM electrode whose surface was covered with a Nafion film. CV2 was obtained with the same electrode in $5 \mathrm{mM}$ glucose and CV3 was obtained with $1 \mathrm{mM}$ of AA, UA and AP added to the glucose solution. CV2 coincides with CV3, indicating the absence of interference.

logical level [1,19] of $1 \mathrm{mM}$ of each of the interfering agents, AA, UA and AP. It is obvious that CV2 coincides with CV3. Therefore, the CVs in Fig. 2c indicate that the electrode showed no response to the presence of the interfering agents within the potential range used in this work.

The NCM electrode's glucose response has been further characterized for small-volume sample and long-term, in vivo applica- 

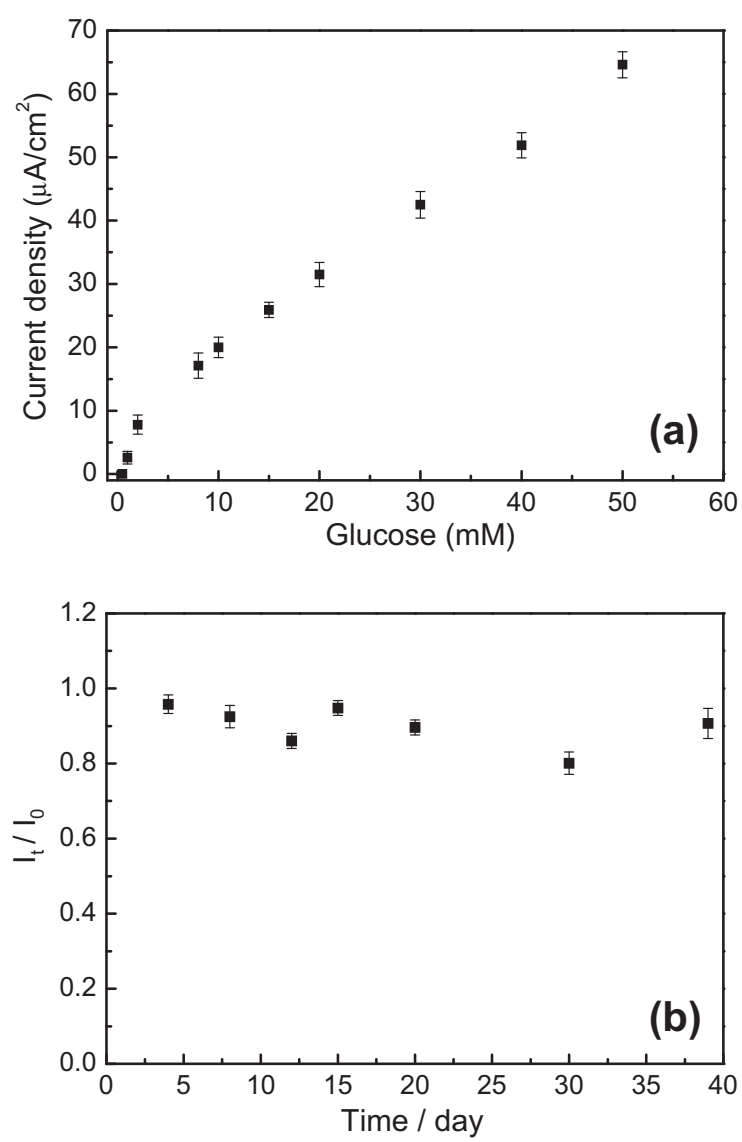

Fig. 3. (a) Glucose calibration curve of the NCM electrode covered by a Nafion film obtained with single $1 \mu \mathrm{l}$ drops of glucose solution. (b) The long-term, in vitro stability of the NCM electrode has been characterized during a period of 40 days. $I_{\mathrm{o}}$ is the electrode's initial amperometric response to $3 \mathrm{mM}$ glucose evaluated at $0.7 \mathrm{~V}$ while $I_{\mathrm{t}}$ is the electrode's subsequent response evaluated under the same conditions. The electrode was stored in PBS between measurements.

tions. The significantly enhanced glucose response provided by the nano-composite material observed suggests that the composite material can be used in detecting glucose in small-volume samples. We have carried out characterization of the sensing properties of the composite material using small-volume glucose samples. The characterization was facilitated by depositing single drops of glucose-containing PBS on the NCM electrode and inserting a $0.015^{\prime \prime}$ diameter $\mathrm{Ag} / \mathrm{AgCl}$ wire into the drop. Fig. 3a shows the glucose calibration curve obtained by putting $1 \mu$ drops of glucose solution on a NCM electrode that was covered with a Nafion membrane. The linear range of the calibration curve is from $0.5 \mathrm{mM}$ to $50 \mathrm{mM}$ with a correlation coefficient $r=0.9909$. The detection limit was estimated to be $16 \mu \mathrm{M}$ according to a signal-to-noise ratio of 3 . The sensitivity of the electrode is $2.2 \mu \mathrm{A} \mathrm{cm}^{-2} \mathrm{mM}^{-1}$. Fig. $3 \mathrm{~b}$ shows the in vitro glucose response of a NCM electrode, measured during a 40 days period. The electrode was stored in PBS between measurements. The result indicates that the electrode was reasonably stable during the testing period with a constant $10 \%$ decrease in the glucose response from its initial value.

The sensitivities and detection limits for glucose obtained using the NCM electrode $\left(2.5 \mu \mathrm{Acm}^{-2} \mathrm{mM}^{-1}, 14 \mu \mathrm{M}\right.$ and 2.2 $\mu \mathrm{A} \mathrm{cm}^{-2} \mathrm{mM}^{-1}, 16 \mu \mathrm{M}$ ) are comparable to those reported works using other non-enzyme sensing elements, e.g. ZnO/Co nanoclusters [20] $\left(13.3 \mu \mathrm{A} \mathrm{cm}^{-2} \mathrm{mM}^{-1}, 20 \mu \mathrm{M}\right)$. We have demonstrated the long-term ( 40 days), in vitro stability of the NCM electrode and characterized the small-volume sample glucose sensing of the NCM electrode in air. Our results indicate the potential of NCM in implanted and small-volume sample applications. These studies were missing in the reported non-enzyme glucose sensors [21].

\section{Conclusions}

In summary, the USiN-based composite material was demonstrated to provide significantly enhanced amperometric response to glucose due to the 3D loading of USiN in the nanoporous structure of PANI. The linear range of the composite material's glucose calibration curve covers both the hypo- and hyper-glycaemic glucose levels with a sensitivity of $2.5 \mu \mathrm{A} \mathrm{cm}^{-2} \mathrm{mM}^{-1}$. The complete selectivity for glucose against interfering agents was achieved by depositing a Nafion membrane on the NCM electrode. Characterization of the glucose response of the composite material with small-volume glucose samples shows similar sensitivity as with large-volume samples. The NCM electrode's long-term in vitro glucose response appeared to be reasonably stable. The results presented in this work shows that the USiN-based composite material generates glucose sensing signal by causing direct electro-oxidation of glucose without the generation of $\mathrm{H}_{2} \mathrm{O}_{2}$ [16], which is known to produce detrimental effect on GOx.

\section{Acknowledgement}

This work was supported by American Diabetes Association (Grant Number 7-08-RA-191).

\section{References}

[1] H.E. Koschwanez, W.M. Reichert, Biomaterials 28 (2007) 3687-3703.

[2] S. Park, H. Boo, T.D. Chung, Anal. Chim. Acta 556 (2006) 46-57.

[3] M.J.AJ. Gerritsen, A. Kros, R.J.M. Nolte, J.A. Lutterman, J. Invest. Surg. 11 (1998) 163-174.

[4] J.D. Newman, A.P.F. Turner, Biosens. Bioelectron. 20 (2005) 2435-2453.

[5] B. Feldman, G. McGarraugh, A. Heller, N. Bohannon, J. Skyler, E. Deleeuw, D. Clarke, Diabetes Technol. THERAP. 2 (2000) 221-229.

[6] G. Wang, K. Mantey, M.H. Nayfeh, S.-T. Yau, Appl. Phys. Lett. 89 (2006) 243901.

[7] A. Sandhu, Nat. Nanotechnol. 2 (2007) 75.

[8] A.P. Kelaidopoulou, G. Kokkinidis, W.T. Napporn, J.-M. Leger, C. Lamy, J. Appl. Electrochem. 29 (1999) 101-107.

[9] R. Bashyam, P. Zelenay, Nature 443 (2006) 63-66.

[10] G. Belomoin, J. Therrien, M. Nayfeh, Appl. Phys. Lett. 77 (2000) 779-781.

[11] S. Rao, J. Sutin, R. Clegg, E. Gratton, M.H. Nayfeh, S. Habbal, A. Tsolakidis, R.M. Martin, Phys. Rev. B 69 (2004) 205319.

[12] A.I. Gopalan, K.P. Lee, D. Ragupathy, S.H. Lee, L.W. Lee, Biomaterials 30 (2009) 5999-6005.

[13] B. Rajesh, K.R. Thampi, J.M. Bonard, H.J. Mathieu, N. Xanthopoulos, B. Viswanathand, Electrochem. Solid-State Lett. 7 (2004) A404-A407.

[14] C.-C. Hu, E. Chen, J.-Y. Lin, Electrochim. Acta 47 (2002) 2741-2749.

[15] E. Wilkins, P. Atanasov, Med. Eng. Phys. 18 (1996) 273-288.

[16] D.W. Schmidtke, A. Heller, Anal. Chem. 70 (1998) 2149-2155.

[17] L. Zhang, S. Dong, J. Anal. Chem. 568 (2004) 189-194.

[18] P. Santhosh, K.M. Manesh, S. Uthayakumar, S. Komathi, A.I. Gopalan, K.-P. Lee, Bioelectrochemistry 75 (2009) 61-66.

[19] R.B. Ames, R. Cathcart, E. Schwiers, P. Hochstein, Proc. Natl. Acad. Sci. USA. 78 (1981) 6858-6862.

[20] Z.W. Zhao, X.J. Chen, B.K. Tay, J.S. Chen, Z.J. Han, K.A. Khor, Biosens. Bioelectron. 23 (2007) 135-139.

[21] Md. Mahbubur Rahman, A.J. Saleh Ahammad, J.-H. Jin, S.J. Ahn, J.-J. Lee, Sensors 10 (2010) 4855-4886. 